\title{
Protocol for the Mason: Health Starts Here prospective cohort study of young adult college students
}

\author{
Alison E. Cuellar ${ }^{1}$, Leah M. Adams², Lilian de Jonge ${ }^{3}$, Virginia Espina ${ }^{4}$, Laurette Espinoza ${ }^{3}$, Sarah F. Fischer ${ }^{5}$, \\ Cara L. Frankenfeld ${ }^{6}$, Denise A. Hines ${ }^{7}$, Olga Kornienko ${ }^{5}$, Heidi Y. Lawrence ${ }^{8}$, Ziaul H. Rana ${ }^{3}$, Niloofar Ramezani ${ }^{9}$, \\ Matthew E. Rossheim ${ }^{6}$, Jerome L. Short ${ }^{5}$, Eric N. Waithaka ${ }^{7}$, Alyssa N. Wilson ${ }^{3}$ and Lawrence J. Cheskin ${ }^{3 *}$
}

\begin{abstract}
Background: Young adulthood is a period of increasing independence for the $40 \%$ of young adults enrolled in U.S. colleges. Previous research indicates differences in how students' health behaviors develop and vary by gender, race, ethnicity, and socioeconomic status. George Mason University is a state institution that enrolls a highly diverse student population, making it an ideal setting to launch a longitudinal cohort study using multiple research methods to evaluate the effects of health behaviors on physical and psychological functioning, especially during the COVID-19 pandemic.

Results: Mason: Health Starts Here was developed as a longitudinal cohort study of successive waves of first year students that aims to improve understanding of the natural history and determinants of young adults' physical health, mental health, and their role in college completion. The study recruits first year students who are 18 to 24 years old and able to read and understand English. All incoming first year students are recruited through various methods to participate in a longitudinal cohort for 4 years. Data collection occurs in fall and spring semesters, with online surveys conducted in both semesters and in-person clinic visits conducted in the fall. Students receive physical examinations during clinic visits and provide biospecimens (blood and saliva).

Conclusions: The study will produce new knowledge to help understand the development of health-related behaviors during young adulthood. A long-term goal of the cohort study is to support the design of effective, lowcost interventions to encourage young adults' consistent performance of healthful behaviors, improve their mental health, and improve academic performance.
\end{abstract}

\section{Background}

The transition from adolescence to adulthood in postindustrial societies varies considerably in duration. It may be an extended and "emerging" period characterized by exploration of identity and human capital acquisition for professional and technological careers [1], or it may be a brief and "accelerated" period in assuming adult roles

\footnotetext{
* Correspondence: Icheskin@gmu.edu

${ }^{3}$ Department of Nutrition and Food Studies, College of Health and Human Services, George Mason University, Peterson Hall 4113, Fairfax, USA Full list of author information is available at the end of the article
}

(e.g., completing school, working fulltime, creating an independent household, or parenting) due to marginalized identities, such as gender, ethnic/racial minority, immigration status, or poverty status [2]. The pace and processes of young adult development and maturation, notably social-cognitive and motivational systems, lay the foundation for self-efficacy, decision-making, and behavioral self-regulation [3]. Further, the transition to attendance at a university is a critical time for establishing and reinforcing healthy or unhealthy behaviors, including those related to nutrition, exercise, sleep, substance

(C) The Author(s). 2021 Open Access This article is licensed under a Creative Commons Attribution 4.0 International License, which permits use, sharing, adaptation, distribution and reproduction in any medium or format, as long as you give appropriate credit to the original author(s) and the source, provide a link to the Creative Commons licence, and indicate if changes were made. The images or other third party material in this article are included in the article's Creative Commons licence, unless indicated otherwise in a credit line to the material. If material is not included in the article's Creative Commons licence and your intended use is not permitted by statutory regulation or exceeds the permitted use, you will need to obtain permission directly from the copyright holder. To view a copy of this licence, visit http://creativecommons.org/licenses/by/4.0/. The Creative Commons Public Domain Dedication waiver (http://creativecommons.org/publicdomain/zero/1.0/) applies to the data made available in this article, unless otherwise stated in a credit line to the data. 
use, and mental health [4]. Approximately $40 \%$ of young adults enroll in a college or university in the US [5], making this a social context of considerable influence during this period of development and maturation. Universities are uniquely positioned to study cohorts of young adults for the assessment and promotion of health. Such research has the potential to yield insights, and guide interventions and policies that improve students' health and educational outcomes.

Mental and physical health issues are leading factors interfering with students' academic performance $[6,7]$. Approximately $32 \%$ of US college and university students report significant mental health symptoms, including depression (17\%), generalized anxiety $(7 \%)$, and suicidal ideation (6\%) [8]. A recent study of 1441 US adults ages 18 to 39 found that the prevalence of depressive symptoms was more than 3 -fold higher during the COVID-19 pandemic compared with before the pandemic [9]. College and university students in the US engage in heavier drinking than their non-college peers [10-12]. Approximately $30 \%$ of these students ages 18 to 22 currently binge drink, and $20 \%$ used an illicit drug within the past month [13]. Additionally, disordered eating behavior, such as binge eating, excessive exercise, and restriction is prevalent among US students $[14,15]$ and linked to all of the mental health conditions described above [16].

By the time they enroll in a college or university, most US students have engaged in sexual behavior at some point in their lifetime $[17,18]$. Rates of sexually transmitted infections (STIs) are highest among those in the traditional undergraduate students' age range [19]. US samples of undergraduate students highlight inconsistent condom or other protective barrier use during sex [17], along with low rates of testing for STIs [20]. US undergraduates, particularly females, report very high rates of dating and intimate partner violence [21]. Studies indicate that an average of $10 \%$ of female students in the US experience at least one sexual assault during the academic year, and rates are especially high among first year students [22, 23]. One recent study of 155,026 students across 196 US campuses found that the percent of students with lifetime mental health diagnoses had increased from 22 to $36 \%$ [24]. Of importance to academic outcomes, students with mental health conditions are at higher risk of dropping out than other students [25]. All these factors underscore the need for improved understanding of emotional and behavioral health during the undergraduate years.

Unfortunately, higher rates of college enrollment have not uniformly translated into increased rates of graduation. Many students drop out or do not complete their degrees in 4 years, which creates a large economic burden nationally $[26,27]$.
Several factors that promote undergraduate students' mental health and the likelihood of completing their degrees in the US have previously been identified. For example, the presence of supportive social networks across multiple systems of relationships, including peers, friends, romantic partners and other adults can support personal and academic success [28]. Recent research has linked supportive social networks to mental health [29] as well as to educational perseverance and achievement [30]. Other psychosocial factors, such as self-perceptions (self-esteem and self-efficacy), attributions (internal control and mastery), motivation (goals and values), and self-regulation (time management and study skills) predict persistence in staying in school and achievement [31]. Further, a variety of young adults' personality strengths, such as meaning in life, hope, grit, gratitude, curiosity, and knowledge of one's strengths have been correlated with reduced psychological symptoms and increased life satisfaction [32].

Other health behaviors known to shift substantially in young adulthood include diet and exercise, which can have considerable long-term implications. Excessive weight gain and higher rates of obesity are among the changes experienced by young adults. Obesity prevalence among young adults in the US is $34 \%$, compared to $20 \%$ among adolescents [33]. Obesity has been found to be a substantial risk factor for, among many other conditions, type-2 diabetes, heart disease, severe osteoarthritis, and mortality [33]. Moreover, this risk is disproportionately experienced by select racial and ethnic groups [30]. While under-researched, ethnic disparities in the prevalence of obesity and excessive weight gain may begin during young adulthood [34-36]. Particularly relevant for US college and university campuses is that obesity has been found to spread along social and family networks [37]. Fortunately, the risk of developing obesity, associated co-morbidities, and their attendant costs may be substantially reduced through even modest (5-10\%) weight loss. Modest weight loss can reduce diabetes risk up to $58 \%$ in individuals with pre-diabetes---a finding consistent for at least 15 years---as well as reduce diabetes-related medical complications [38-40].

Rates of physical activity fall sharply in the US when young adults transition from high school to undergraduate years [41]. This decline is associated with a variety of factors, from psychosocial, to levels of self-efficacy, and to perceived health benefits. Despite the health benefits of physical activity, among them improved cognitive abilities and lower stress, college students face many demands on their time, including academics and work. Previous studies in the US have found that students with higher fitness levels have lower credit loads and study less than students with lower fitness levels, underscoring the trade-offs that students may face [42]. Students' 
physical activity is related to better academic performance. Data from US university and college students has found that adequate physical activity, sleep, and diet were positive predictors of grade point averages [43], which opens the doors to a variety of novel studies and interventions that can target not just health but also academic and employment outcomes. Numerous questions remain among young adults, including the role of social media exposure in physical activity, differences in physical activity levels by socioeconomic status, ethnicity, culture, gender and other health factors, and whether low-cost, effective interventions can be designed to encourage participation in exercise, improved eating habits, improved academic performance and improved mental health.

Overall, previous evidence points to the importance of capturing the undergraduate experience early on, because experiences during the first year are predictive of continued enrollment in post-secondary education [44]. For example, in the US, excess stress during the first semester has been found to be a predictor of poor academic performance, and further, poor academic performance in the first year predicts attrition [45]. Further, it has been observed that many maladaptive health behavior patterns begin in the first year and remain stable throughout later undergraduate years $[46,47]$.

In contrast to the many other studies of young adults which, like those cited above, focus on specific aspects of students' behaviors and health, the Mason: Health Starts Here was developed as a longitudinal cohort study to examine a broad range of physical health, mental health, and undergraduate degree completion determinants among successive waves of young adults who are first-time, first year university students. The overall goal is thus to improve understanding of the natural history and trajectories of young adults' behaviors and health during undergraduate years. Of particular interest and utility would be to better characterize factors which increase the likelihood of current and future problems ('risk factors'), or reduce those risks ('protective factors'). It is anticipated that the study will produce new knowledge to support the design of low-cost interventions to encourage adoption of healthful behaviors, improve mental health, and improve academic performance among young adults.

\section{Methods}

\section{Objectives and study design}

Mason: Health Starts Here is a longitudinal cohort study of first-time, first year university students. Its objectives are:

- to examine health, health behavior, and mental health as predictors of college completion;
- to examine the applicability of emerging adulthood or accelerated adulthood theories to college students who differ by socioeconomic status, sexual orientation, ethnicity, culture, gender, and other demographic factors;

- to examine nutrition and physical activity levels during the college years, a time of increasing adult independence

- to examine differences in longitudinal associations among physical and psychological health factors by socioeconomic status, sexual orientation, ethnicity, culture, gender, and other demographic factors;

- to examine how social network influences and social media modulate healthful and unhealthful behaviors;

- to examine how social connectedness and trauma exposures may impact mental and physical health;

- to examine how current and past risky behaviors, sexual risk, gun ownership, and substance use modulate health, mental health, and successful college completion; and

- to identify modifiable risk and protective factors to inform new interventions to improve health and well-being.

Data collection occurs each fall and spring semester, and each cohort is followed for 4 years. Each fall and spring semester, participants will be contacted to participate in online questionnaires. Each fall, they will also be asked to participate in an in-person physical exam in a research center which includes biospecimen collection. Saliva will be collected in all 4 years, and blood will only be collected during years 1 and 4 . The longitudinal capture of data is illustrated in Fig. 1, along with timing of incentives.

\section{Study population}

The study includes first year students who are 18 to 24 years old who are able to read and understand English. First year students are defined as students who are newly embarking on a four-year undergraduate degree at George Mason University. The goal is to recruit 300 participants each year.

\section{Study hypothesis, power calculation and data analysis}

While a number of hypotheses will be tested, the power calculation was based on the hypothesis that alcohol consumption predicts student drop-out. For the optimal sample size procedure, predicting students' drop-out based on their alcohol consumption, and other factors including demographics, and using measures from previous studies [48], we will have a power of 0.8, type I error rate of 0.05 , a confidence level of $95 \%$, and a fairly small odds ratio of 1.7 to detect an approximate effect size of 0.3 . The estimated sample size for examining if students 


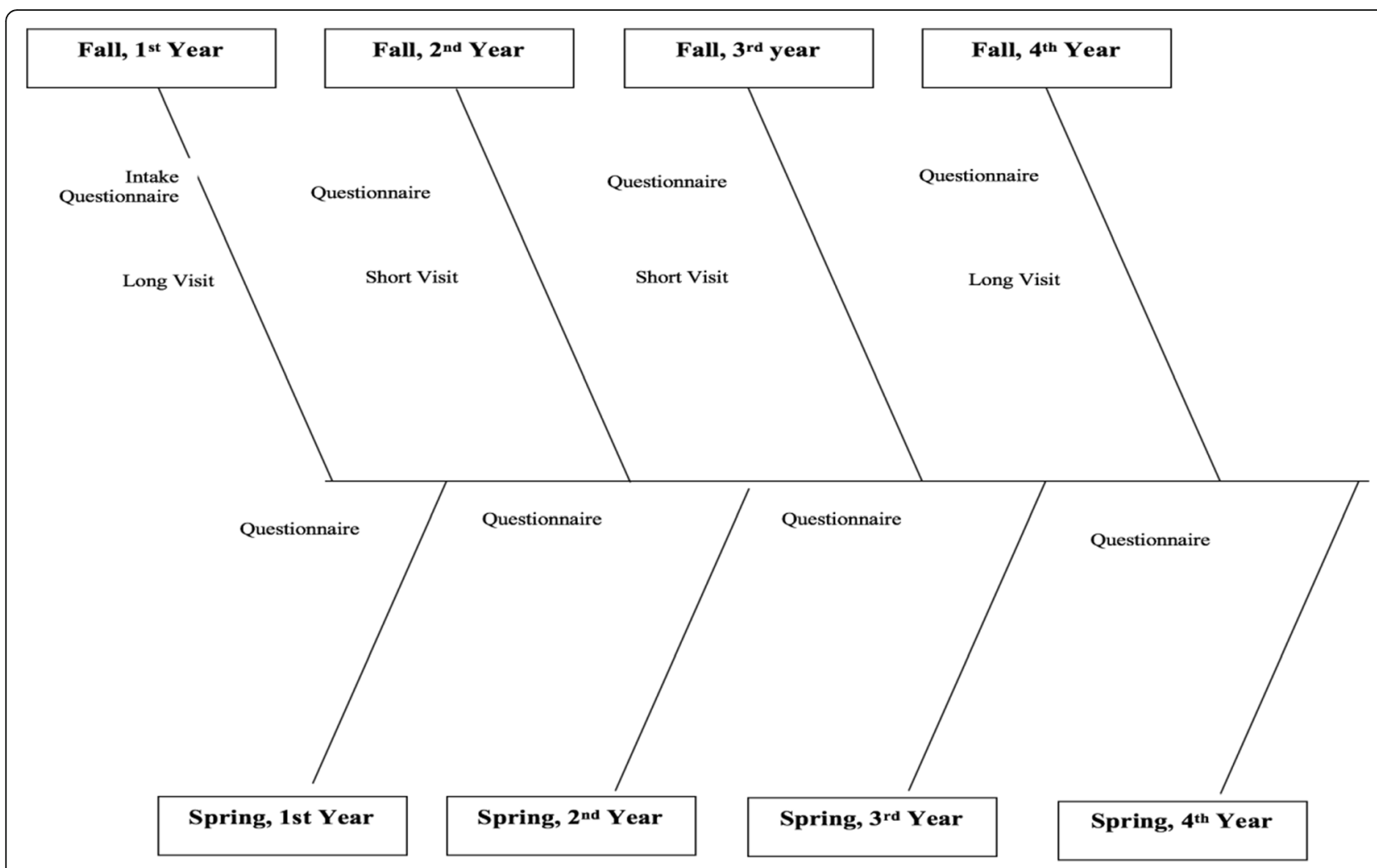

Fig. 1 Schema of recruitment times, questionnaire administration, and study visits for the full study

are more likely to drop out of college during their first year when they have higher alcohol consumption is about 465 students, a sample size which is planned to be achieved by the end of the second year of the study. Power analysis was performed using SAS 9.4 [49].

Upon completion of the longitudinal data collection and data exploration procedures, young adults' indicators of physical and mental health, demographic variables, and other factors such as firearm access, substance use, technology and social media use, and measures of nutrition, physical activity and sleep will be used in longitudinal models to evaluate their role in their college completion and other outcomes of interest. Depending on the research question, the following longitudinal approaches will be used to identify the factors that influence college completion and other response variables of interest over time. General linear models and generalized linear models will be fitted when the dependent variables are continuous and non-continuous, respectively. Generalized estimating equations will be used instead when distributional assumptions are not met [50]. For assessing individual changes over time, while accounting for the clustering of observations within different cohorts, colleges, or any other cluster which results in similar behavior (i.e. hierarchical data), a random intercept growth hierarchical linear model will be fitted [51].

Performing such models and analyzing the trend of events over time allows us to gain an insight into students' physical and mental well-being while they complete their college education [52]. Additionally, these modeling approaches will result in robust model selections and inferences [53]. Within these models, we will correct for the "cohort effect"-that is allowing for analysis of the individual time components of cohort (range of birth dates or when they started college), period (current time), and age (at point of measurement)-and will account for the impact of each individually.

\section{Recruitment and retention}

We are using a purposive, convenience sample that is being recruited to have similar demographic characteristics to the university's diverse student population. In the pilot year (academic year 2019-2020), the study was advertised to students in selected courses with large numbers of first year enrollees through flyers outside of classrooms, brief in-class presentations and to select student organization, online video, postcards distributed in class, and email. Beginning in 2020, contact information of incoming first year students was obtained from 
University Life and recruitment was expanded to all incoming first year students reached through invitation letters and emails, along with video and information during first year orientation sessions, and messages to followers on University social media. Additional recruitment occurs by asking faculty teaching courses with high proportions of first year students to share the recruitment video with their classes. Because of COVID-19, in 2020-2021 all recruitment is virtual, but once a higher proportion of in-person classes and student organizations resume in future years, in-person presentations about the study will resume.

Once participants complete an online survey, they are invited to make an appointment for an in-person physical exam and biospecimen collection. Participants are offered $\$ 10$ for completing each online survey and an additional \$25 for completing each in-person visit. Participants receive personalized health feedback based on their survey responses and physical exam. To encourage study retention, participants receive survey reminder emails and birthday emails. Participants are asked to provide contact information of friends or family to facilitate follow-up. The study team also delivers healthrelated messages to the participant community, such as tips for stress management, and will share summary study findings when available.

\section{Data collection}

The study includes online and in-person data collection. Table 1 lists all study measures and the timing of data collection.

\section{Online questionnaire}

The online data collection focuses on physical and emotional health, nutrition, sleep, civic engagement, and academic success. Note that some instruments/measures have not been evaluated specifically in 18-24 year olds, which the current study will help researchers to assess.

\section{Demographics and social determinants of health}

These items include age, race, ethnicity, mother's and father's education, current employment status and hours worked, whether the participant lives on campus, romantic relationship status, religious preference, country of birth for participant and parents, sexual identity, current gender, and gender at birth. Adult food security was assessed using two items adapted from the Hunger Vital Sign screener [98]: "1) I worried about not having enough to eat and 2) I tried not to eat a lot so that the food would last." The response options are: often true, sometimes true, never true. Housing insecurity was assessed using two items adapted from the Veterans Screener [99]: "In the past 2 months, have you been living in stable housing that you own, rent, or stay in as part of a household?" and "Are you worried or concerned that in the next 2 months you may NOT have stable housing that you own, rent, or stay in as part of a household?" Both questions are answered with a yes or no.

\section{Health}

Self-rated health (SRH) is measured with one item that asks, "Would you say your health is excellent, very good, good, fair, or poor?" Responses range from 1 (poor) to 5 (excellent). SRH is strongly correlated with objective health status [70].

\section{Migraine}

The presence of migraine and migraine severity is assessed using the American Migraine Prevalence and Prevention (AMPP) diagnostic module (7 items) [66] and the Migraine Disability Assessment (MIDAS) questionnaire (7 items) [67], respectively.

\section{Nutrition, physical activity, and sleep}

Respondents are asked to self-report height and weight. Habitual dietary and supplement intake is assessed using the Diet History Questionnaire (DHQ)-III food frequency questionnaire, a 161-item tool which asks about food intake over the past month [108]. Physical activity is measured with the International Physical Activity Questionnaire (IPAQ) - short version, a 7-item questionnaire [109]. Sleep quality is measured with 24 items from the Pittsburgh Sleep Quality Index or PSQI [86]. The PSQI items form seven component scores that range from 0 to 3 points. Some items are fill-in-the blank and others have four choices to measure sleep quality, latency, duration, efficiency, disturbances, medication, and dysfunction during the past month. The scale has a test-retest reliability of 0.87 overall, and 0.53 to 0.81 for the different components [110].

\section{Technology use and social media}

Technology Use is measured with questions about 10 types of social media and amount of use with a 10-point response scale [100]. Online Status Indicators [101] are measured with 4 questions with a 5-point response scale of how important number of followers and likes are on social media to them [101]. The Social Media Integration Subscale [102] consists of 6 questions with a 5point response scale. To assess emotional investment in social media, a modification of the Social Integration and Emotional Connection subscale of the Social Media Use Integration Scale [102] will be used. Nighttimespecific Social Media is measured with seven items rated from Never [1] to Daily [7]. 
Table 1 Descriptions, points of data collection, and references of the measures included in the study

\begin{tabular}{|c|c|c|c|c|c|}
\hline & $\begin{array}{l}\text { Baseline } \\
\text { Only }\end{array}$ & Fall & Spring & Citation & $\begin{array}{l}\text { \# of } \\
\text { items }\end{array}$ \\
\hline \multicolumn{6}{|l|}{ Online Survey } \\
\hline Demographics & & $x$ & $x$ & & \\
\hline Financial Support & & $x$ & & [54] & 1 \\
\hline Disability/ability Status & & $x$ & & & 1 \\
\hline Anger, Depression, Anxiety & & $x$ & $x$ & {$[55]$} & 21 \\
\hline Loneliness & & $x$ & $x$ & {$[56]$} & 4 \\
\hline PTSD & & $x$ & $x$ & [57] & 20 \\
\hline Alcohol Use Disorders & & $x$ & $x$ & {$[58]$} & 10 \\
\hline 30 Day Alcohol Use NSDUH & & $x$ & $x$ & {$[59]$} & 1 \\
\hline 30 Day Binge Drinking NSDUH/BRFSS & & $x$ & $x$ & {$[59,60]$} & 1 \\
\hline 30 Day Drinking Max BRFSS & & $x$ & $x$ & {$[60]$} & 1 \\
\hline 30 Day Drinking and Driving YRBS/NSDUH & & $X$ & $x$ & {$[59,61]$} & 1 \\
\hline 30 Day Driving Under Influence YRBS/NSDUH & & $X$ & $x$ & {$[59,61]$} & 1 \\
\hline Riding with Drinking Driver YRBS & & $x$ & $x$ & [61] & 1 \\
\hline Drug Use & & $x$ & $x$ & {$[62]$} & 10 \\
\hline Vaping E-cigarette & & $x$ & $x$ & {$[60]$} & 2 \\
\hline Cigarette Smoking & & $x$ & $x$ & [11] & 1 \\
\hline Cigarette Smoking, 30 Days & & $x$ & $x$ & {$[59]$} & 1 \\
\hline Cigarette Menthol, 30 Days & & $x$ & $x$ & {$[59]$} & 1 \\
\hline Marijuana Use & & $x$ & $x$ & {$[60]$} & 3 \\
\hline Eating Disorders & & $x$ & $x$ & [63] & 31 \\
\hline Rumination & & $x$ & & [64] & 4 \\
\hline Perceived Stress & & $x$ & $x$ & {$[65]$} & 4 \\
\hline Migraine Severity & $x$ & & & {$[66,67]$} & 14 \\
\hline Life Satisfaction & & $X$ & $x$ & [68] & 5 \\
\hline Happiness & & $x$ & $x$ & {$[69]$} & 4 \\
\hline Self-Rated Health & & $x$ & $x$ & [70] & 1 \\
\hline Life Events Checklist, Baseline and Follow-up & $x$ & & $x$ & [71] & 17,9 \\
\hline Sexual History, Contraceptive Use, Perceived Risk, and PrEP Knowledge & $x$ & & $x$ & {$[72-76]$} & $\begin{array}{l}42,2 \\
3,4\end{array}$ \\
\hline Sexual Experiences, Baseline and Follow-up & $x$ & & $x$ & [77] & 10 \\
\hline Adverse Childhood Experiences & $x$ & & & [78] & 10 \\
\hline Dating Violence & & $x$ & & [61] & 9 \\
\hline Online Dating Violence & & $x$ & & [79] & 2 \\
\hline Everyday Inequity & & $x$ & $x$ & {$[80]$} & 6 \\
\hline Ethnic Identity Scale, Baseline & $x$ & & $x$ & {$[81]$} & 9 \\
\hline Language Brokering Scale & $x$ & & & {$[82]$} & 1 \\
\hline Social Connectedness & & $x$ & & [83] & 10 \\
\hline Impulsivity/Impulse Control & & $x$ & & [84] & 21 \\
\hline Physical Activity & & $X$ & $x$ & {$[85]$} & 7 \\
\hline Texting/e-mailing While Driving & & $x$ & & {$[61]$} & 1 \\
\hline Sleep Quality & & $X$ & $x$ & [86] & 24 \\
\hline Gratitude & & $x$ & $x$ & {$[87]$} & 6 \\
\hline Hope & & $x$ & $x$ & {$[88]$} & 8 \\
\hline
\end{tabular}


Table 1 Descriptions, points of data collection, and references of the measures included in the study (Continued)

\begin{tabular}{|c|c|c|c|c|c|}
\hline & $\begin{array}{l}\text { Baseline } \\
\text { Only }\end{array}$ & Fall & Spring & Citation & $\begin{array}{l}\text { \# of } \\
\text { items }\end{array}$ \\
\hline Meaning in Life & & $x$ & $x$ & [89] & 5 \\
\hline Perceived Social Support & & $x$ & $x$ & [90] & 12 \\
\hline Mini Personality Scale & & $x$ & & [91] & 20 \\
\hline Personal Network/Social Structure & & $x$ & $x$ & {$[92,93]$} & 23 \\
\hline USDA + Personalized Feedback & & $x$ & & [94] & 4 \\
\hline Food/Personal Care Products & & $x$ & & [95] & 44 \\
\hline Sustainable Consumption Behavior Nutrition & & $x$ & & [96] & 18 \\
\hline New Environmental Paradigm & & $x$ & & [97] & 15 \\
\hline Food Insecurity & & $x$ & & [98] & 2 \\
\hline Housing Security & & $x$ & & [99] & 2 \\
\hline Past and Anticipated Voting & & $x$ & & & 7 \\
\hline Technology Use & & $x$ & $x$ & [100] & 11 \\
\hline Online Status Indicators & & $x$ & & [101] & 4 \\
\hline Social Media Integration Scale & & $x$ & & [102] & 6 \\
\hline Night-Time Social Media Use & & $x$ & $x$ & [103] & 7 \\
\hline DHQ-III Food Frequency & & $x$ & & [104] & 135 \\
\hline Self-Compassion & & & $x$ & [105] & 26 \\
\hline Compassion & & & $x$ & [106] & 16 \\
\hline \multicolumn{6}{|l|}{ In-Person Clinic Visit } \\
\hline Health History Form & $x$ & & & & \\
\hline $\begin{array}{l}\text { Physical Exam (body weight, height, waist circumference, blood pressure, pulse, respiratory rate, } \\
\text { current oral temperature, heart and lung exam, abdominal exam, neck exam, and general physical } \\
\text { appearance) }\end{array}$ & $x$ & & & & \\
\hline Self-Injurious Thoughts and Behaviors (SITBI) & $x$ & & & [107] & 25 \\
\hline Saliva Collection & & $x$ & & & \\
\hline Blood Collection & $x$ & & & & \\
\hline Urine Collection & $x$ & & & & \\
\hline Body Composition via DXA Scan & $x$ & & & & \\
\hline Resting Metabolic Rate via Fitmate & $x$ & & & & \\
\hline Stool Kit Collection (Optional) & $x$ & & & & \\
\hline
\end{tabular}

\section{Perceived risk of sexually transmitted infection, contraceptive use and sexual history}

Sexual behavior and attitudes are measured with a total of 51 modified items about sexual behaviors (42 items) [72], types of contraceptives (2 items) [73], perceived risk and susceptibility to sexually transmitted infections (3 items) [74], and PrEP knowledge (4 items) [75, 76].

The Sexual Experiences Survey (SES) [77] asks participants whether or not they have experienced unwanted sexual contact via a number of different means. The questionnaire has been modified to ask participants if they have experienced each type of unwanted sexual assault since the age of 14 and in the past 3 months. Participants respond 'yes' or 'no' to a series of 10 questions describing sexual assault experiences [77].

\section{Firearms}

There are 30 questions assessing a variety of firearm related topics including: acquisition, ownership, access, proximity, safe storage, training, carrying behavior, reasons for carrying, and firearm type, as well as whether they knew someone who was unintentional or intentional shot. These items were adapted from several national surveys including the National Firearm Survey, Pew Research Center, National Comorbidity Survey Adolescent Supplement (NCS-AS), as well as from previously conducted research $[111,112]$.

\section{Substance use}

Alcohol use is measured with the Alcohol Use Disorders Identification Test (AUDIT), a 10-item scale assessing 
alcohol consumption, drinking behaviors, and alcoholrelated problems, which is used to identify individuals at risk of an alcohol use disorder [58]. The psychometric properties of the AUDIT have been extensively examined in multiple age groups, including undergraduate drinkers [113]. Internal consistency is above .70 in these samples. Degree of Problems Related to Drug Abuse is measured using the 10-item Drug Abuse Screening Test (DAST) [62]. Similarly, the psychometric properties of the DAST are well established in multiple samples, including young adults, and internal consistency and test re-test reliabilities range from .70s to .90 s [114]. Ever smoking cigarettes, past 30-day cigarette smoking, and 30-day menthol cigarette smoking items were used/ adapted from the Monitoring the Future (MTF) study and National Survey on Drug Use and Health (NSDUH). Vaping/electronic cigarette (e-cigarette) use was measured using items from the MTF study, modified with nicotine clarification as part of the instructions per the Behavioral Risk Factor Surveillance System (BRFSS).

Past 30-day alcohol consumption items were measured using or adapting items from the NSDUH and BRFSS. Marijuana use was measured using three items from the BRFSS: ever use (yes/no), past 30-day use frequency, and manner of use (i.e., smoke, eat, drink, vaporize, dab, don't know, unsure). Risky driving-related behaviors (i.e., driving under the influence of alcohol, riding in a vehicle driven by someone who had been drinking, driving under the influence of marijuana, and texting or emailing while driving) were assessed using items from the NSDUH and YRBSS or adapting them (i.e., past 30day rather than 12 month).

\section{Access to health care}

Health psychiatric medication, history of mental health treatment, health insurance, regular source of care and barriers to access. These are measured by "If you have ever been prescribed or currently prescribed psychiatric medicine" with a "Yes" or "No."

\section{Psychological symptoms}

Eating Disorder risk and symptoms are measured with the Eating Pathology Symptoms Inventory (EPSI) [63]. The EPSI is a 45-item multidimensional measure of eating pathology and includes items related to body dissatisfaction as well as restricted eating and binge eating. Internal consistency for the subscales ranges from .84-.89; the measure has been validated in large samples of undergraduate men and women [115].

Anger, Depression, and Anxiety symptoms are measured with the Patient Reported Outcomes Measurement Information System (PROMIS) [116]. The PROMIS assesses individual functioning across various domains of well-being and has been extensively validated in multiple age groups (including young adults) as part of a large multi-year initiative by the National Institute of Health to develop a patient reported outcome measurement system and assessment center. Respondents report their feelings of these emotions over the past 7 days using a 5-point Likert scale ('Never' to 'Always'). Internal consistency in a large undergraduate sample is high (depression $=.94$, anxiety $=.92$, and anger $=89$ ).

Loneliness is measured with 4 items from the Short Scale for Measuring Loneliness measure [56]. Items are scored on a 3-point scale from "hardly ever" to "often," with an internal consistency of .72. The short form is highly correlated with the long form of this measure [56], and has demonstrated predictive and concurrent validity in young adults and undergraduates [117].

Post-Traumatic Stress Disorder symptoms are measured with 20 items rated from 0 (not at all) to 4 (extremely) using the Posttraumatic Stress Disorder Checklist for DSM-5 (PCL-5) [57]. The PCL-5 has been validated in undergraduate and military samples [57, 118 ] with internal consistency reported as high as .95 in undergraduates.

Impulsivity/Impulse control is measured with the 56 item UPPS-P [84]. The UPPS-P consists of five scales assessing conscientiousness, lack of planning, sensation seeking, and acting impulsivity during periods of positive and negative mood. Participants are asked to rate their typical behavior on a scale from 1 to 5 . The UPPS-P was initially developed and validated with young adult and undergraduate samples and its' psychometric properties have been extensively tested in young adults and clinical populations. Internal consistency of the subscales typically ranges from the .80 s to the .90 s $[84,119]$.

\section{Psychological well-being}

Life Satisfaction is measured with 5 items from the Satisfaction with Life Scale (SWLS) [68]. Items are rated on 7-point scale from 'strongly disagree' to 'strongly agree.' The SWLS is a single factor with an alpha coefficient of .87 and test-retest reliability of $.82[68]$.

- Happiness is measured with 4 items from the widely used Subjective Happiness Scale (SHS) [69]. Internal consistency typically ranges from .74 to .94 . The items are rated on 7-point scales with various response choices.

- Gratitude is measured with 6 items from the Gratitude Questionnaire [87]. The items are rated on 7-point scale from 'strongly disagree' to 'strongly agree.' McCullough et al. [87] reported an alpha coefficient of .82 for this measure.

- Hope is measured with the 8-item Adult Hope Scale [88]. The AHS measures two facets of hope: Agency, or goal-directed energy, and Pathways, or planning 
to meet goals. Items are rated on an 8-point scale from 'definitely false' to 'definitely true.' Goodman et al. [32] reported an alpha coefficient of .87 for this measure.

- Meaning in Life is measured with 5 items from the presence subscale of the Meaning in Life Questionnaire [89]. Items are rated on a 7-point scale from 'absolutely untrue' to 'absolutely true.' Goodman et al. [32] reported an alpha coefficient of .90 for this measure.

- The Ethnic Identity Scale - Brief (EIS-B) [81] consists of 9 items that examine three different domains of ethnic identity formation: exploration (3 items), resolution (3 items), and affirmation (3 items).

Responses are coded so that higher scores on each subscale indicate greater exploration, resolution, and affirmation. Internal consistency has been shown for subscales, and ranged from .70 to .89 [81]. The threefactor structure has been found with Latino adolescents, and an ethnically diverse (majority and minority) sample of college students [83, 120].

- The Compassion Scale [106] and the short form of the Self-Compassion Scale [121] are measured with 16 items, and 12 items, respectively, of how you feel and behave (on a scale from 1 'Almost Never' to 5 'Almost Always.')

\section{Psychological risk variables}

The Life Events Checklist [71] is a 17-item measure asking participants to check experiences related to any of 17 potentially-traumatic events (e.g. natural disaster, accident, combat exposure) listed. Participants are asked to check one or more of the following statements: 'Happened to me'; 'Witnessed it'; 'Learned about it'; 'Not sure'; and 'Doesn't apply'.

Adverse Childhood Experiences assesses all types of abuse, neglect, and other potentially traumatic experiences that may be experienced by people under the age of 18 by asking participants to respond "yes" or "no" to the occurrence of 10 events in two categories: abuse (psychological, physical, and sexual) and household dysfunction (substance use, mental illness, physical violence, and criminal behavior). The prevalence of exposure is computed by summing across the abuse and household dysfunction categories [78].

Everyday Inequity Scale is a 5-item scale asking participants to report frequency, from 'never' to 'at least once a week', and reasons for experiencing racial and nonracial discrimination in their day-to-day life [80, 122]. Internal consistency for this scale is .77.

\section{Peers and social support}

Perceived Social Support is measured with 12 items from the Multidimensional Scale of Perceived Social
Support [90]. The items are rated on a 5-point scale from 1 (strongly disagree) to 5 (strongly agree) for relationships with family, friends, and a significant other. The overall alpha coefficient is .85 and ranges from .72 to .85 for the three types of relationships [90].

Personal network composition and structure Individuals report on up to 5 members of their personal networks with whom they discuss important matters. For each of these members they provide information on individual characteristics (e.g., gender, race/ethnicity, education, nature of relationship, frequency and mode of communication), rated positive and negative quality of their relationship with each network member, and estimated likelihood that network members know one another. Similar assessments have been used in large-scale aging surveys, such as the National Social Life, Health, and Aging Project (NSHAP) [92] and Chicago Health, Aging, and Social Relations Study (CHASRS) [93].

Personality traits The Mini-IPIP [91] is a 20-item short form of the 50-item International Personality Item PoolFive-Factor Model Measure [123]. The scale measures extraversion, agreeableness, conscientiousness, neuroticism, and intellect/imagination, with 4 items for each trait. The items are rated on a 5-point scale from 1 (very inaccurate) to 5 (very accurate).

\section{Environment and sustainability}

Environmental orientation is assessed with the 4-item revised New Environmental Paradigm Scale (NAPS) [97]. Sustainable consumption is measured with the 18item Sustainable Consumption Behavior Scale (SCBS) [124]. The NAPS is used to uncover attitudes and beliefs in relation to the environment, while the SCBS measures what, if any, sustainable practices individuals are currently utilizing.

\section{Environmental exposures}

Exposures related to food, employment and personal care products [124] includes 12 items related to purchases of food and personal care items and their packaging, 2 items related to second-hand smoke, 3 questions related to type of work, and 3 items related to products used in the home.

\section{Assessment in the research center (in-person visit)}

During the in-person visit to the population health clinic, study participants are asked additional questions about their medical history, given a history and physical exam by a clinician, and asked to donate a venous blood sample and a saliva sample. Participants are requested to fast prior to their appointment and to avoid taking 
medications and engaging in rigorous physical activity within an hour of their appointment.

At intake, participants are asked for medical history and family history using a checklist of conditions, including indictors of cardiovascular-related health issues, such as high blood pressure, heart disease, stroke, high cholesterol, chest pain, and irregular heartbeat. Participants also complete a past hospitalizations list, a weight history by age, a current medications list, two items on perceived problematic gambling and shopping; six questions on meal timing and meal frequency; and a source and frequency of purchased meals checklist; and two questions on wake-up time that day and participants' usual wake-up time. Women are asked to report on a 15-item menstrual history. Participants are also asked to complete an interviewer-guided Self-Injurious Thoughts and Behaviors Interview (SITBI). This is a 25 -item instrument that queries lifetime and past week selfinjurious thoughts and behaviors [107]. The physical exam includes body weight, height, waist circumference, blood pressure, pulse, respiratory rate, current oral temperature, heart and lung exam, abdominal exam, neck exam, and general physical appearance. Body composition is measured using a DXA scanner (DXA, Hologic Horizon densitometer; Hologic, Boston MA). Resting metabolic rate is measured using indirect calorimeter (FitMatePro, Cosmed, Rome, Italy).

\section{Biospecimens}

Participants are asked to fill two cryovials with approximately $1 \mathrm{~mL}$ of saliva using passive drool procedures. Blood samples include a venous blood draw of $36 \mathrm{~mL}$. Samples are tested for HbA1c, lipid panels, and blood chemistries. Abnormal results are communicated to participants by clinical staff. The remaining sample is processed, aliquoted, and frozen at -70 degrees $\mathrm{C}$.

\section{Discussion}

The purpose of the Mason Cohort study is to launch a longitudinal study using multiple research methods in a racially and ethnically diverse population of young adults to evaluate the effects of health behaviors on physical and psychological functioning, especially during the COVID-19 pandemic. The study will produce new knowledge to help understand the development of health-related behaviors during young adulthood. A long-term goal is to support the design of effective, lowcost interventions to encourage young adults' consistent performance of healthful behaviors, improve their mental health, and improve academic performance and completion of undergraduate degrees.

The Mason Cohort was thus envisioned as also being a tool to potentially benefit participants directly, in addition to benefitting our understanding as researchers in health fields. Thus, it is a hybrid design, part traditional cohort study and part intervention trial.

This has obvious benefits to participants, as information and advice concerning their own health and risk factors are returned to them, and interest in improving those risks is potentially fostered. The study design also encourages researchers, stimulated by data gathered and associations discerned to propose sub-studies, which, upon review and approval by the study steering committee are submitted for IRB review and offered to all or subsets of cohort participants based on the specific questions being asked in the sub-study. Preference will be given to proposed sub-studies which offer a direct potential benefit to study participants.

While most longitudinal cohort studies are by design, purely observational, and thus, at best of indirect benefit to participants, even these may show expectancy effects. For example, participants may be triggered to answer survey questions "appropriately" (so-called "reactivity" effects), or to address unfavorable health-related behaviors through merely being asked about them [125].

From an evaluation of theories on college student retention and success, interactionalist theory of social and academic integration suggests that college completion relies upon the extent to which students are committed to their institution, and this commitment level depends on the level of social and academic integration, determined by the quality of interactions [126]. The student attrition model, focused more on cognitive and behavioral aspects of college completion, posits a significant role for perceptions of satisfaction and attitude impacting behavioral intentions to stay or leave [127]. Besides, results from different interventions on college students suggest that low cost and brief interventions can have a meaningful impact on long-term student outcomes [128]. Therefore, this study will follow a multi-stage developmental process for preventive interventions (following Institute of Medicine recommendations); the identification of a target problem, then the review and investigation of research that can identify protective factors and inform etiologic models, and finally, preventive interventions targeting these factors using experimental designs and intervention analyses [129].

As noted in Methods, we are using a purposive, convenience sample that we will recruit to have similar demographic characteristics to the university's diverse student population. If some demographic groups are underrepresented in our initial recruitment, such as nonbinary gender, ethnic/racial minority, and diverse sexual identities, we will contact various campus organizations and support groups where they are members to encourage participation in our study.

The self-selected population is a popular sampling technique in many health areas that require human 
subjects and is an effective sampling strategy, especially in experimental research settings [130]. Since the potential research subjects contact study staff directly, this can reduce the amount of time necessary to search for appropriate participants. In addition, the potential participants are likely to be committed to taking part in the study, which can help improve attendance and a greater willingness to provide more insight into the phenomena being studied. However, with self-selection potential research participants may exhibit an inherent bias in their characteristics and approach to the study [131].

To complete any study of living beings, it is critical to retain study participants. Participants who complete their scheduled follow-up visits within predefined visit windows will be considered as retained. Although every effort is being taken to facilitate completing each participant's entry, mid, and exit visits, attrition can and does happen; and the retention rate can fluctuate over time and across visits [132]. To ensure continued participation and minimize attrition, this study follows the key precepts of retention and practice: facilitating participation, communicating study progress, expressing appreciation, and informing participants of study results [133].

We see the future of the study as promising- its breadth of coverage of health predictors and precursors, its diverse sample of young college students, and its flexible implementation strategies enhance its capacity to inform emerging health problems and risk factors through examination of the wealth of data and specimens being gathered.

Also of note is the benefit of having baseline specimens and surveys in a diverse sample of young adults when new health problems like COVID-19 emerge.

More work needs to be done, though, including securing sources of ongoing funding, and developing collaborations with other studies of young adults/college students. Future enhancements being considered include following participants for a time frame beyond the undergraduate years to track behavioral and health trajectories across the lifespan, and gathering more family data, including adding parents and future offspring of current participants.

\begin{abstract}
Acknowledgments
The authors wish to acknowledge the following people for contributing to the content of the survey and recruitment materials and processes utilized in the study: Anna Pollack, PhD, Jhumka Gupta, PhD, Robert McGrath, PhD, Rebecca Sutter, DNP, and Xiaoquan Zhao, PhD.

The following students and staff are acknowledged for their indispensable contributions to recruitment and retention of participants, and logistical support for the study: Tsedey Afrassa, Sana Ahmad, Ruth Baghi, Arminda Carballo, Beth Foote, Rui Gu, Egette Indele, Tanisha Demessa, Eleanor Speidel, Rosemarie Karmanac, DNP, Valerie Cruz Ortiz, Fatima Nayani, Naomi Pak, Tarang Parekh, Christopher Reyes, Sally Rucker, and Katherine Warner.
\end{abstract}

\section{Authors' contributions}

All authors have approved the submitted version of the manuscript describing this work, and have agreed both to be personally accountable for their own contributions and to ensure that questions related to the accuracy or integrity of any part of the work, even ones in which the author was not personally involved, are appropriately investigated, resolved, and the resolution documented in the literature. Conception and design of the work: AEC, LJC. Writing or substantially revising the manuscript: LUC, AEC, JLS, SFF, LE. Analysis of the data: ZHR, NR, CLF. Review and editing of final manuscript- AEC, LJC, OK, NR, LMA, LD, VE, LE, SFF, CLF, DAH, HYL, ZHR, MER, JLS, ENW, ANW

\section{Funding}

Provided by the Institute for Biohealth Innovation of the George Mason University. The funder had no role in the design of the study and collection, analysis, and interpretation of data, nor in writing this manuscript.

\section{Availability of data and materials}

The datasets generated during the current study are not publicly available to ensure privacy of individual-level data, but upon reasonable request. Deidentified data are available through the corresponding author after review and approval by the Study Steering Committee.

\section{Declarations}

Ethics approval and consent to participate

was conducted by George Mason University's Office of Research Integrity and Assurance via its Institutional Review Board, which approved the protocol on June 10, 2019 under IRB\#1432539. Written/digital informed consent for study participation will be obtained from all subjects. For the online survey portion of the study, potential participants were enrolled and consented online. A separate, written informed consent was obtained for the in-person physical examination. All methods were carried out in accordance with relevant guidelines and regulations, along with the IRB approval. The signed consent notes to whom and under what circumstances information disclosed by participants may be acted upon. Participants were screened for suicidal ideation and intention, and referred or walked over by staff to Student Health if they endorsed activity that was concerning.

\section{Consent for publication}

No individually identified data has been disclosed and thus publication consent is not applicable.

\section{Competing interests}

The authors declare that they have no competing interests.

\section{Author details}

${ }^{1}$ Department of Health Administration and Policy, George Mason University, Fairfax, USA. ${ }^{2}$ Departments of Psychology, and of Women \& Gender Studies, George Mason University, Fairfax, USA. ${ }^{3}$ Department of Nutrition and Food Studies, College of Health and Human Services, George Mason University, Peterson Hall 4113, Fairfax, USA. ${ }^{4}$ Center for Applied Proteomics and Molecular Medicine, George Mason University, Fairfax, USA. ${ }^{5}$ Department of Psychology, George Mason University, Fairfax, USA. ${ }^{6}$ Department of Global and Community Health, George Mason University, Fairfax, USA. ${ }^{7}$ Department of Social Work, George Mason University, Fairfax, USA. ${ }^{8}$ Department of English, George Mason University, Fairfax, USA. 'Department of Statistics, George Mason University, Fairfax, USA.

Received: 25 November 2020 Accepted: 4 May 2021

Published online: 12 May 2021

\section{References}

1. Arnett JJ. Emerging adulthood: a theory of development from the late teens through the twenties. Am Psychol. 2000;55(5):469-80. https://doi. org/10.1037/0003-066X.55.5.469.

2. Lee J, Waithaka $E$. The intersections of marginalized social identities in the transition to adulthood: a demographic profile. Emerg Adulthood. 2017;5(3): 151-63. https://doi.org/10.1177/2167696816659021.

3. Masten AS, Burt KB, Roisman Gl, Obradovic J, Long JD, Tellegen A. Resources and resilience in the transition to adulthood: continuity and change. Dev Psychopathol. 2004;16(04):1071-94.

4. Simons-Morton B, Haynie D, O'Brien F, Lipsky L, Bible J, Liu D. Variability in measures of health and health behavior among emerging adults 1 year 
after high school according to college status. J Am Coll Heal. 2017;65(1):5866. https://doi.org/10.1080/07448481.2016.1238384.

5. National Center for Education Statistics. College enrollment rates. 2019. Available from: https://nces.ed.gov/programs/coe/indicator_cpb.asp.

6. Eisenberg D, Golberstein E, Hunt JB. Mental health and academic success in college. BE J Econ Anal Policy. 2009;9(1) [cited 2020 Oct 27]. Available from: http://www.degruyter.com/view/j/bejeap.2009.9.1/bejeap.2009.9.1.2191/ bejeap.2009.9.1.2191.xml.

7. Ruthig JC, Marrone S, Hladkyj S, Robinson-Epp N. Changes in college student health: implications for academic performance. J Coll Stud Dev. 2011;52(3):307-20. https://doi.org/10.1353/csd.2011.0038.

8. Eisenberg D, Hunt J, Speer N. Mental health in American colleges and universities: variation across student subgroups and across campuses. J Nerv Ment Dis. 2013;201(1):60-7. https://doi.org/10.1097/NMD.0b013e31827a b077.

9. Ettman CK, Abdalla SM, Cohen GH, Sampson L, Vivier PM, Galea S. Prevalence of depression symptoms in US adults before and during the COVID-19 pandemic. JAMA Netw Open. 2020;3(9):e2019686. https://doi. org/10.1001/jamanetworkopen.2020.19686.

10. Blanco C, Okuda M, Wright C, Hasin DS, Grant BF, Liu S-M, et al. Mental health of college students and their non-college-attending peers: results from the National Epidemiologic Study on alcohol and related conditions. Arch Gen Psychiatry. 2008;65(12):1429-37. https://doi.org/10.1001/archpsyc. 65.12.1429.

11. Johnston L, O'Malley P, Bachman J, Schulenberg J. Monitoring the future national survey results on drug use, 1975-2000. Volume II: college students and adults ages 19-40. In: NIH publication no. 10-7585. Bethesda: National Institute on Drug Abuse; 2010.

12. Johnston LD, O'Malley PM, Bachman JG, Schulenberg JE. Monitoring the future national survey results on drug use, 1975-2012: volume I, secondary school students. [internet]. Ann Arbor: Institute for Social Research, The University of Michigan; 2013. Available from: https://deepblue.lib.umich.edu/ bitstream/handle/2027.42/137921/mtf-vol1_2012.pdf?sequence=1

13. Lipari $R$, Jean-Francois $B$. Trends in perception of risk and availability of substance use among full-time college students. In: The CBHSQ Report [Internet]. Rockville (MD): Substance Abuse and Mental Health Services Administration (US); 2013. [cited 2020 Oct 28]. Available from: http://www. ncbi.nlm.nih.gov/books/NBK396151/.

14. Goldschmidt AB, Wall MM, Zhang J, Loth KA, Neumark-Sztainer D. Overeating and binge eating in emerging adulthood: 10-year stability and risk factors. Dev Psychol. 2016;52(3):475-83. https://doi.org/10.1037/ dev0000086.

15. Trojanowski PJ, Adams LM, Fischer S. Understanding profiles of student binge drinking and eating: the importance of motives. Addict Behav. 2019; 96:148-55. https://doi.org/10.1016/j.addbeh.2019.04.025.

16. Eisenberg D, Nicklett EJ, Roeder K, Kirz NE. Eating disorder symptoms among college students: prevalence, persistence, correlates, and treatmentseeking. J Am Coll Heal. 2011;59(8):700-7. https://doi.org/10.1080/074484 81.2010.546461.

17. American College Health Association. American College Health Association National College Health Assessment II: Reference Group Executive Summary Spring 2018. Silver Spring: American College Health Association; 2018. Available from: https:/www.acha.org/documents/ncha/NCHA-II_Spring_201 8_Reference_Group_Executive_Summary.pdf

18. Cavazos-Rehg PA, Krauss MJ, Spitznagel EL, Schootman M, Bucholz KK, Peipert JF, et al. Age of sexual debut among US adolescents. Contraception. 2009 Aug 1;80(2):158-62. https://doi.org/10.1016/j.contraception.2009.02.014.

19. Whiting W, Pharr JR, Buttner MP, Lough NL. Behavioral Interventions to Increase Condom Use Among College Students in the United States: A Systematic Review. Health Educ Behav. 2019 [cited 2020 Nov 20]; Available from;46(5):877-88. https://doi.org/10.1177/1090198119853008.

20. Lindley LL, Sharif AM, Chowdhury T. College students' comfort with and intention to use self-collection services for STI testing. J Am Coll Heal. 2020; 0(0):1-10. https://doi.org/10.1080/07448481.2020.1820511.

21. Knowledge Networks, Inc. 2011 College Dating Violence and Abuse Poll. Liz Claiborne, Inc.; 2011.

22. Cantor D, Fisher B, Chibnall S, Harps S, Townsend R, Thomas G, et al. Report on the AAU Campus Climate Survey on Sexual Assault and Misconduct 2020. 2020.

23. Krebs C, Lindquist C, Berzofsky M, Shook-Sa B, Peterson K. Campus Climate Survey Validation Study Final Technical Report; 2016. p. 218.
24. Lipson SK, Lattie EG, Eisenberg D. Increased rates of mental health service utilization by U.S. college students: 10-year population-level trends (20072017). Psychiatr Serv. 2019;70(1):60-3. https://doi.org/10.1176/appi.ps.201 800332.

25. Kochhar-Bryant C, Bassett DS, Webb KW. Transition to Postsecondary Education for Students With Disabilities. Corwin Press; 2009. p. 249.

26. National Center for Education Statistics. The Condition of Education 2019 (NCES 2019-144). 2019. Available from: https://nces.ed.gov/fastfacts/display.a sp?id=40.

27. Schneider M, Yin L (Michelle). The Hidden Costs of Community Colleges: (537212012-001): American Psychological Association; 2011. [cited 2020 Oct 28]. Available from: http://doi.apa.org/get-pe-doi.cfm?doi=10.1037/e537212 012-001

28. Barry CM, Madsen SD, DeGrace A. Growing up with a little help from their friends in emerging adulthood. In: The Oxford handbook of emerging adulthood. New York: Oxford University Press; 2016. p. 215-29. (Oxford library of psychology).

29. Mason MJ, Zaharakis N, Benotsch EG. Social Networks, substance use, and mental health in college students. J Am Coll Heal. 2014 Oct 3;62(7):470-7. https://doi.org/10.1080/07448481.2014.923428.

30. Stadtfeld C, Vörös A, Elmer T, Boda Z, Raabe IJ. Integration in emerging social networks explains academic failure and success. Proc Natl Acad Sci. 2019;116(3):792-7. https://doi.org/10.1073/pnas.1811388115.

31. Fong CJ, Davis CW, Kim Y, Kim YW, Marriott L, Kim S. Psychosocial factors and community college student success: a meta-analytic investigation. Rev Educ Res. 2017;87(2):388-424. https://doi.org/10.3102/0034654316653479.

32. Goodman FR, Disabato DJ, Kashdan TB, Machell KA. Personality strengths as resilience: a one-year multiwave study. J Pers. 2017;85(3):423-34. https://doi. org/10.1111/jopy.12250.

33. Dietz WH. Obesity and excessive weight gain in young adults: new targets for prevention. JAMA. 2017 Jul 18;318(3):241-2. https://doi.org/10.1001/ja ma.2017.6119.

34. Bruce MA, Beech BM, Thorpe RJ, Griffith DM. Racial disparities in sugarsweetened beverage consumption change efficacy among male first-year college students. Am J Mens Health. 2016;10(6):NP168-75. https://doi.org/1 $0.1177 / 1557988315599825$

35. Sarathy H, Henriquez G, Abramowitz MK. Abdominal obesity, race and chronic kidney disease in young adults: results from NHANES 1999-2010. PLoS One. 2016;11(5):e0153588. https://doi.org/10.1371/journal.pone.0153 588.

36. VanKim NA, Laska MN. Socioeconomic disparities in emerging adult weight and weight behaviors. Am J Health Behav. 2012;36(4):433-45. https://doi. org/10.5993/AJHB.36.4.1.

37. Christakis NA, Fowler $\mathrm{JH}$. The spread of obesity in a large social network over 32 years. N Engl J Med. 2007;357(4):370-9. https://doi.org/10.1056/ NEJMsa066082.

38. Diabetes Prevention Program Research Group. 10-year follow-up of diabetes incidence and weight loss in the diabetes Prevention program outcomes study. Lancet. 2009;374(9702):1677-86. https://doi.org/10.1016/S0140-673 6(09)61457-4.

39. Diabetes Prevention Program Research Group. The 10-year costeffectiveness of lifestyle intervention or metformin for diabetes Prevention: an intent-to-treat analysis of the DPP/DPPOS. Diabetes Care. 2012;35(4):72330. https://doi.org/10.2337/dc11-1468.

40. Diabetes Prevention Program Research Group. Long-term effects of lifestyle intervention or metformin on diabetes development and microvascular complications over 15-year follow-up: the diabetes Prevention program outcomes study. Lancet Diabetes Endocrinol. 2015;3(11):866-75.

41. Calestine J, Bopp M, Bopp CM, Papalia Z. College student work habits are related to physical activity and fitness. Int J Exerc Sci. 2017 Nov 1;10(7): 1009-17.

42. Stults-Kolehmainen MA, Sinha R. The effects of stress on physical activity and exercise. Sports Med. 2014 Jan 1;44(1):81-121. https://doi.org/10.1007/ s40279-013-0090-5.

43. Wald A, Muennig PA, O'Connell KA, Garber CE. Associations between healthy lifestyle behaviors and academic performance in U.S. undergraduates: a secondary analysis of the American college health Association's National College Health Assessment II. Am J Health Promot. 2014;28(5):298-305. https://doi.org/10.4278/ajhp.120518-QUAN-265.

44. Turner $P$, Thompson E. College retention initiatives meeting the needs of millennial freshman students. Coll Stud J. 2014;48(1):94-104. 
45. Amirkhan JH, Kofman YB. Stress overload as a red flag for freshman failure and attrition. Contemp Educ Psychol. 2018;54:297-308. https://doi.org/10.1 016/j.cedpsych.2018.07.004.

46. Lyzwinski LN, Caffery L, Bambling M, Edirippulige $\mathrm{S}$. The relationship between stress and maladaptive weight-related behaviors in college students: a review of the literature. Am J Health Educ. 2018;49(3):166-78. https://doi.org/10.1080/19325037.2018.1449683.

47. Wilson OWA, Bopp CM, Papalia Z, Duffey M, Bopp M. Freshman physical activity constraints are related to the current health behaviors and outcomes of college upperclassmen. J Am Coll Heal. 2020;0(0):1-7.

48. Jennison KM. The short-term effects and unintended Long-term consequences of binge drinking in college: a 10-year follow-up study. Am J Drug Alcohol Abuse. 2004 Jan 1;30(3):659-84. https://doi.org/10.1081/ADA-2 00032331

49. SAS Institute Inc. SAS/ETS ${ }^{\oplus 13.2}$ User's Guide. Cary: SAS Institute Inc; 2014

50. Zeger SL, Liang K-Y. Longitudinal data analysis for discrete and continuous outcomes. Biometrics. 1986 Mar;42(1):121-30. https://doi.org/10.2307/2531248.

51. Bryk AS, Raudenbush SW. Application of hierarchical linear models to assessing change. Psychol Bull. 1987;101(1):147-58. https://doi.org/10.1037/ 0033-2909.101.1.147.

52. Caruana EJ, Hernández-Sánchez J, Solli P. Longitudinal studies. J Thorac Dis. 2015;7(11):E537-40. https://doi.org/10.3978/j.issn.2072-1439.2015.10.63.

53. Zeger SL, Liang K-Y. An overview of methods for the analysis of longitudinal data. Stat Med. 1992;11(14-15):1825-39. https://doi.org/10.1002/sim.4 780111406.

54. Cinamon R. Integrating work and study among young adults: testing an empirical model. J Career Assess. 2016;24(3):527-42. https://doi.org/10.11 77/1069072715599404.

55. Riley W, Rothrock N, Bruce B, Christodolou C, Cook K, Hahn E, et al. Patientreported outcomes measurement information system (PROMIS) domain names and definitions revisions: further evaluation of content validity in IRTderived item banks. Qual Life Res. 2010;19(9):1311-21. https://doi.org/10.1 007/s11136-010-9694-5.

56. Hughes M, Waite L, Hawkley L, Cacioppo J. A short scale for measuring loneliness in large surveys: results from two population-based studies. Res Aging. 2004:26(6):655-72. https://doi.org/10.1177/0164027504268574.

57. Blevins C, Weathers F, Davis M. The posttraumatic stress disorder checklist for DSM-5 (PCL-5): development and initial psychometric evaluation. J Trauma Stress. 2015;28(6):489-98. https://doi.org/10.1002/jts.22059.

58. Saunders J, Aasland O, Babor T, de la Fuente J, Grant M. Development of the alcohol use disorders identification test (AUDIT): WHO collaborative project on early detection of persons with harmful alcohol consumption--II. Addiction. 1993;88(6):791-804. https://doi.org/10.1111/j.1360-0443.1993.tb02 093.x

59. Abuse S, Administration MHS. Results from the 2011 National Survey on drug use and health: summary of National Findings [internet]. NSDUH series H-44, HHS publication no. (SMA) 12-4713. Substance Abuse and Mental Health Services Administration: Rockville, MD; 2012. Available from: https:// store.samhsa.gov/product/Results-from-the-2011-National-Survey-on-DrugUse-and-Health-Summary-of-National-Findings/SMA12-4713

60. Centers for Disease Control and Prevention (CDC). Behavioral Risk Factor Surveillance System Survey Data [Internet]. 2005. Available from: https:// www.cdc.gov/brfss/about/index.htm. Accessed 1 Jan 2021.

61. Centers for Disease Control and Prevention (CDC). High School Youth Risk Behavior Survey Data [Internet]. 1991-2019:2019 Available from: http://nccd. cdc.gov/youthonline/. Accessed 1 Jan 2021.

62. Skinner $\mathrm{H}$. The drug abuse screening test. Drug Abuse Screening Test Addict Behav. 1982;7(4):363-71. https://doi.org/10.1016/0306-4603(82 )90005-3.

63. Forbush K, Wildes J, Pollack L, Dunbar D, Luo J, Patterson K, et al. Development and validation of the eating pathology symptoms inventory (EPSI). Psychol Assess. 2013;25(3):859-78. https://doi.org/10.1037/a0032639.

64. Garnefski N, Kraaij V. Cognitive emotion regulation questionnairedevelopment of a short 18-item version (CERQ-short). Individ Dif. 2006:41(6): 1045-53. https://doi.org/10.1016/j.paid.2006.04.010

65. Cohen S, Kamarck T, Mermelstein R. A global measure of perceived stress. J Health Soc Behav. 1983;24(4):385-96. https://doi.org/10.2307/2136404.

66. Lipton R, Stewart W, Diamond S, Diamond M, Reed M. Prevalence and burden of migraine in the United States: data from the American migraine study II. Headache. 2001;41(7):646-57. https://doi.org/10.1046/j.1526-4610.2 $001.041007646 . x$
67. Stewart W, Lipton R, Kolodner K, Sawyer J, Lee C, Liberman J. Validity of the migraine disability assessment (MIDAS) score in comparison to a diarybased measure in a population sample of migraine sufferers. Pain. 2000; 88(1):41-52. https://doi.org/10.1016/S0304-3959(00)00305-5.

68. Diener E, Emmons R, Larsen R, Griffin S. The satisfaction with life scale. J Assess. 1985;49(1):71-5. https://doi.org/10.1207/s15327752jpa4901_13.

69. Lyubomirsky S, Lepper H. A measure of subjective happiness: preliminary reliability and construct validation. Soc Indic Res. 1999;46(2):137-55. https:// doi.org/10.1023/A:1006824100041.

70. Meng Q, Xie Z, Zhang T. A single-item self-rated health measure correlates with objective health status in the elderly: A survey in suburban Beijing. Front Public Health. 214;2:27. https://doi.org/10.3389/fpubh.2014.00027.

71. Gray M, Litz B, Hsu J, Lombardo T. Psychometric properties of the life events checklist. Assessment. 2004;11(4):330-41. https://doi.org/10.1177/10731911 04269954.

72. Mustanski B, Starks T, Newcomb ME. Methods for the design and analysis of relationship and partner effects on sexual health. Arch Sex Behav. 2014 Jan; 43(1):21-33. https://doi.org/10.1007/s10508-013-0215-9.

73. Trussell J, Aiken A, Micks E, Guthrie K. Efficacy, safety, and persona considerations. In: contraceptive technology. 21st ed. New York: Ayer Company Publishers, Inc.; 2018.

74. Pollack LM, Boyer CB, Weinstein ND. Perceived risk for sexually transmitted infections aligns with sexual risk behavior with the exception of condom nonuse: data from a nonclinical sample of sexually active young adult women. Sex Transm Dis. 2013 May 1;40(5):388-94. https://doi.org/10.1097/ OLQ.0b013e318283d2e5.

75. Mosley T, Khaketla M, Armstrong HL, Cui Z, Sereda P, Lachowsky NJ, et al. Trends in awareness and use of HIV PrEP among gay, bisexual, and other men who have sex with men in Vancouver, Canada 2012-2016. AIDS Behav 2018;22(11):3550-65. https://doi.org/10.1007/s10461-018-2026-4.

76. Janulis P, Newcomb ME, Sullivan P, Mustanski B. Evaluating HIV knowledge questionnaires among men who have sex with men: a multi-study item response theory analysis. Arch Sex Behav. 2018;47(1):107-19. https://doi. org/10.1007/s10508-016-0910-4.

77. Koss M, Gidycz C. Sexual experiences survey: reliability and validity. J Consult Clin Psychol. 1985;53(3):422-3. https://doi.org/10.1037/0022-006X.53.3.422.

78. Felitti V, Anda R, Nordenberg D, Williamson D, Spitz A, Edwards V, et al. Relationship of childhood abuse and household dysfunction to many of the leading causes of death in adults. The adverse childhood experiences (ACE) study. Am J Prev Med. 1998;14(4):245-58. https://doi.org/10.1016/S0749-3 797(98)00017-8

79. Kernsmith P, Victor B, Smith-Darden J. Online, offline, and over the line: coercive sexting among adolescent dating partners. Youth Soc. 2018;50(7): 891-904. https://doi.org/10.1177/0044118X18764040.

80. Sternthal M, Slopen N, Williams D. Racial disparities in health: how much does stress really matter? Bois Rev. 2011;8(1):95-113. https://doi.org/10.1017/ S1742058X11000087.

81. Douglass S, Umaña-Taylor A. A brief form of the ethnic identity scale: development and empirical validation. Identity. 2015;15(1):48-65. https://doi. org/10.1080/15283488.2014.989442.

82. Shen Y, Kim S, Wang Y, Chao R. Language brokering and adjustment among Chinese and Korean American adolescents: a moderated mediation model of perceived maternal sacrifice, respect for the mother, and motherchild open communication. Asian Am J Psychol. 2014;5(2):86-95. https://doi. org/10.1037/a0035203.

83. Yoon $\mathrm{E}$, Jung $\mathrm{K}$, Lee $\mathrm{R}$, Felix-Mora M. Validation of social connectedness in mainstream society and the ethnic community scales. Cult Divers Ethn Minor Psychol. 2012;18(1):64-73. https://doi.org/10.1037/a0026600.

84. Cyders MA, Littlefield AK, Coffey S, Karyadi KA. Examination of a short English version of the UPPS-P impulsive behavior scale. Addict Behav. 2014; 39(9)1372-6. https://doi.org/10.1016/j.addbeh.2014.02.013.

85. IPAQ Research Committee. Guidelines for data processing and analysis of the International Physical Activity Questionnaire (IPAQ)-short and long forms [Internet]. 2005. Available from: http://www.ipaq.ki.se/scoring.pdf. Accessed 1 Jan 2021.

86. Buysse D, Reynolds C III, Monk T, Berman S, Kupfer D. The Pittsburgh sleep quality index: a new instrument for psychiatric practice and research. Psychiatry Res. 1989;28(2):193-213. https://doi.org/10.1016/0165-1781(89)90047-4.

87. McCullough M, Emmons R, Tsang J. The grateful disposition: a conceptual and empirical topography. J Pers Soc Psychol. 2002;82(1):112-27. https://doi. org/10.1037/0022-3514.82.1.112. 
88. Snyder C, Harris C, Anderson J, Holleran S, Irving L, Sigmon S. The will and the ways: development and validation of an individual-differences measure of hope. J Pers Soc Psychol. 1991;60(4):570-85. https://doi.org/10.1037/ 0022-3514.60.4.570.

89. Steger M, Frazier $P$, Oishi $S$, Kaler M. The meaning in life questionnaire: assessing the presence of and search for meaning in life. J Couns Psychol. 2006;53(1):80-93. https://doi.org/10.1037/0022-0167.53.1.80.

90. Zimet G, Dahlem N, Zimet S, Farley G. The multidimensional scale of perceived social support. J Assess. 1988;52(1):30-41. https://doi.org/10.1207/ s15327752jpa5201_2.

91. Donnellan M, Oswald F, Baird B, Lucas R. The mini-IPIP scales: tiny-yeteffective measures of the big five factors of personality. Psychol Assess. 2006;18(2):192-203. https://doi.org/10.1037/1040-3590.18.2.192.

92. Cornwell B, Schumm L, Laumann E, Kim J, Kim Y. Assessment of social network change in a national longitudinal survey. J Gerontol Ser B Psychol Sci Soc Sci. 2014;69(Suppl 2):75-82.

93. Cacioppo J, Hawkley L, Thisted R. Perceived social isolation makes me sad: 5-year cross-lagged analyses of loneliness and depressive symptomatology in the Chicago health, aging, and social relations study. Psychol Aging. 2010;25(2):453-63. https://doi.org/10.1037/a0017216.

94. Gerrior S, Juan W, Basiotis P. An easy approach to calculating estimated energy requirements. Prev Chronic Dis. 2006;3(4):A129.

95. Sathyanarayana S, Barrett E, Nguyen R, Redmon B, Haaland W, Swan S. First trimester phthalate exposure and infant birth weight in the infant development and environment study. Int J Env Res Public Health. 2016; 13(10):945. https://doi.org/10.3390/ijerph13100945.

96. Geiger S, Fischer D, Schrader U. Measuring what matters in sustainable consumption: an integrative framework for the selection of relevant behaviors. Sustain Dev. 2018;26(1):18-33. https://doi.org/10.1002/sd.1688.

97. Dunlap RE, Van Liere KD, Mertig AG. Jones. Measuring endorsement of the new ecological paradigm: a revised NEP scale. J Soc Issues. 2000;56(3):42542. https://doi.org/10.1111/0022-4537.00176.

98. Hager E, Quigg A, Black M, Coleman S, Heeren T, Rose-Jacobs R, et al. Development and validity of a 2-item screener to identify families at risk for food insecurity. Pediatrics. 2010;126(1):26-32.

99. Montgomery A, Fargo J, Kane V, Culhane D. Development and validation of an instrument to assess imminent risk of homelessness among veterans. Public Health Rep. 2014;129(5):428-36. https://doi.org/10.1177/0033354 91412900506.

100. Ohannessian C. Does technology use moderate the relationship between parental alcoholism and adolescent alcohol and cigarette use? Addict Behav. 2009;34(6-7):606-9. https://doi.org/10.1016/j.addbeh.2009.01.001.

101. Nesi J, Choukas-Bradley S, Prinstein M. Transformation of adolescent peer relations in the social media context: part 1-a theoretical framework and application to dyadic peer relationships. Clin Child Fam Psychol Rev. 2018; 21(3):267-94. https://doi.org/10.1007/s10567-018-0261-x.

102. Jenkins-Guarnieri M, Wright $S$, Johnson B. Development and validation of a social media use integration scale. Psychol Pop Media Cult. 2013;2(1):38-50. https://doi.org/10.1037/a0030277.

103. Auxier B, Rainie L, Anderson M, Perrin A, Kumar M, Turner E. Americans and privacy: concerned, confused and feeling lack of control over their personal information. Internet, Science \& Tech: Pew Research Center; 2019.

104. Diet History Questionnaire, Version 3.0. National Institutes of Health, Epidemiology and Genomics Research Program, National Cancer Institute. 2018. https://epi.grants.cancer.gov/dhq3.

105. Neff K. The development and validation of a scale to measure selfcompassion. Self Identity. 2003;2(3):223-50. https://doi.org/10.1080/152 98860309027

106. Pommier E, Neff K, Tóth-Király I. The development and validation of the compassion scale. Assessment. 2020;27(1):21-39. https://doi.org/10.1177/1 073191119874108

107. Nock M, Holmberg E, Photos V, Michel B. Self-injurious thoughts and behaviors interview: development, reliability, and validity in an adolescent sample. Psychol Assess. 2007;19(3):309-17. https://doi.org/10.1037/1040-3590.19.3.309.

108. Kipnis V, Subar AF, Midthune D, Freedman LS, Ballard-Barbash R, Troiano RP, et al. Structure of dietary measurement error: results of the OPEN biomarker study. Am J Epidemiol. 2003 Jul 1;158(1):14-21. https://doi.org/10.1093/aje/ kwg091.

109. Mäder URS, Martin BW, Schutz Y, Marti B. Validity of four short physical activity questionnaires in middle-aged persons. Med Sci Sports Exerc. 2006; 38(7):1255-66. https://doi.org/10.1249/01.mss.0000227310.18902.28.
110. Backhaus J, Junghanns K, Broocks A, Riemann D, Hohagen F. Test-retest reliability of the Pittsburgh sleep quality index (PSQI) in patients with primary insomnia. J Psychosom Res. 2002;53(3):737-40. https://doi.org/10.1 016/S0022-3999(02)00330-6.

111. Miller M, Hepburn L, Azrael D. Firearm acquisition without background checks. Ann Intern Med. 2017 Jan 3;166(4):233-9. https://doi.org/10.7326/M16-1590.

112. Rowhani-Rahbar A, Lyons VH, Simonetti JA, Azrael D, Miller M. Formal firearm training among adults in the USA: results of a national survey. Inj Prev J Int Soc Child Adolesc Inj Prev. 2018;24(2):161-5. https://doi.org/10.113 6/injuryprev-2017-042352.

113. Barry AE, Chaney BH, Stellefson ML, Dodd V. Evaluating the psychometric properties of the AUDIT-C among college students. J Subst Use. 2015 Jan 2; 20(1):1-5. https://doi.org/10.3109/14659891.2013.856479.

114. Yudko E, Lozhkina O, Fouts A. A comprehensive review of the psychometric properties of the drug Abuse screening test. J Subst Abus Treat. 2007 Mar; 32(2):189-98. https://doi.org/10.1016/j.jsat.2006.08.002.

115. Forbush KT, Wildes JE, Hunt TK. Gender norms, psychometric properties, and validity for the eating pathology symptoms inventory. Int J Eat Disord. 2014;47(1):85-91. https://doi.org/10.1002/eat.22180.

116. Cella D, Riley W, Stone A, Rothrock N, Reeve B, Yount S, et al. The patientreported outcomes measurement information system (PROMIS) developed and tested its first wave of adult self-reported health outcome item banks: 2005e2008. J Clin Epidemiol. 2010;63(11):1179-94. https://doi.org/10.1016/j. jclinepi.2010.04.011.

117. Moeller RW, Seehuus M. Loneliness as a mediator for college students' social skills and experiences of depression and anxiety. J Adolesc. 2019 Jun; 73:1-13. https://doi.org/10.1016/j.adolescence.2019.03.006.

118. Ashbaugh AR, Houle-Johnson S, Herbert C, El-Hage W, Brunet A. Psychometric validation of the English and French versions of the posttraumatic stress disorder checklist for DSM-5 (PCL-5). PLoS One. 2016 Oct 10;11(10):e0161645. https://doi.org/10.1371/journal.pone.0161645.

119. Cyders MA. Impulsivity and the sexes: measurement and structural invariance of the UPPS-P impulsive behavior scale. Assessment. 2013 Feb; 20(1):86-97. https://doi.org/10.1177/1073191111428762.

120. Umaña-Taylor AJ, Shin N. An examination of ethnic identity and self-esteem with diverse populations: exploring variation by ethnicity and geography. Cultur Divers Ethnic Minor Psychol. 2007;13(2):178-86. https://doi.org/10.103 7/1099-9809.13.2.178.

121. Raes F, Pommier E, Neff K, Van Gucht D. Construction and factorial validation of a short form of the self-compassion scale. Clin Psychol Psychother. 2011;18(3):250-5. https://doi.org/10.1002/cpp.702.

122. Williams DR, Yu Y, Jackson JS, Anderson NB. Racial differences in physical and mental health: socio-economic status. Stress and Discrimination J Health Psychol. 1997 Jul 1;2(3):335-51. https://doi.org/10.1177/13591053 9700200305.

123. Goldberg L. A broad-bandwidth, public domain, personality inventory measuring the lower-level facets of several five-factor models. In: Personality psychology in Europe. Tilburg, The Netherlands: Tilburg University Press; 1999. p. 7-28.

124. Dunlap $R$. The new environmental paradigm scale: from marginality to worldwide use. J Environ Educ. 2008;40(1):3-18. https://doi.org/10.3200/ JOEE.40.1.3-18.

125. Mitchum AL, Kelley CM, Fox MC. When asking the question changes the ultimate answer: Metamemory judgments change memory. J Exp Psychol Gen. 2016;145(2):200-19. https://doi.org/10.1037/a0039923.

126. Draper S. Tinto's model of student retention [internet]. 2008. Available from: https://www.psy.gla.ac.uk/ steve/localed/tinto.html

127. Aljohani O. A comprehensive review of the major studies and theoretical models of student retention in higher education. High Educ Stud. 2016;6(2): 1. https://doi.org/10.5539/hes.v6n2p1.

128. Harackiewicz JM, Priniski SJ. Improving student outcomes in higher education: the science of targeted intervention. Annu Rev Psychol. 2018; 69(1):409-35. https://doi.org/10.1146/annurev-psych-122216-011725.

129. American Psychological Association. Guidelines for prevention in psychology. Am Psychol. 2014 Apr;69(3):285-96. https://doi.org/10.1037/a0034569.

130. Creighton N, Purdie S, Soeberg M, Walton R, Baker D, Young J. Self-selection in a population-based cohort study: impact on health service use and survival for bowel and lung cancer assessed using data linkage. BMC Med Res Methodol. 2018;18(1):84. https://doi.org/10.1186/s12874-018-0537-3.

131. Khazaal $Y$, Van Singer M, Chatton A, Achab S, Zullino D, Rothen S, et al. Does self-selection affect samples' representativeness in online surveys? An 
investigation in online video game research. J Med Internet Res. 2014;16(7): 164.

132. Abshire M, Dinglas V, Cajita M, Eakin M, Needham D, Himmelfarb C.

Participant retention practices in longitudinal clinical research studies with high retention rates. BMC Med Res Methodol. 2017;17(1):1-10.

133. Gibaldi J, Siddiqi B. Retention strategies for keeping participants engaged. Appl Clin Trials. 2019;28(9):20-1.

\section{Publisher's Note}

Springer Nature remains neutral with regard to jurisdictional claims in published maps and institutional affiliations.

Ready to submit your research? Choose BMC and benefit from:

- fast, convenient online submission

- thorough peer review by experienced researchers in your field

- rapid publication on acceptance

- support for research data, including large and complex data types

- gold Open Access which fosters wider collaboration and increased citations

- maximum visibility for your research: over $100 \mathrm{M}$ website views per year

At BMC, research is always in progress.

Learn more biomedcentral.com/submissions 